\title{
Septal Aperture and Osteoarthritis-The Same or Independent Origins?
}

\author{
Anna Myszka, Dawid Trzciński \\ Department of Human Evolutionary Anthropology, Institute of Anthropology, Faculty of Biology, Adam \\ Mickiewicz University, Poznań, Poland \\ Email: myszanka@amu.edu.pl
}

Received 5 December 2014; accepted 30 March 2015; published 3 April 2015

Copyright (C 2015 by authors and Scientific Research Publishing Inc.

This work is licensed under the Creative Commons Attribution International License (CC BY).

http://creativecommons.org/licenses/by/4.0/

(c) (i) Open Access

\begin{abstract}
Many theories have been suggested in order to explain the etiology of septal aperture (SA), however the problem has not been solved yet. The aim of the study was to examine the relationship between septal aperture and osteoarthritic changes. The skeletal material had come from a medieval cemetery in Cedynia, Poland. Skeletons of 201 adults had been examined. Septal aperture of humeral bone had been scored. Osteoarthritic changes (osteophytosis, porosity, eburnation) of articular surfaces of distal end of humerus and proximal end of ulna had been examined. In the present study female right bones with septal aperture were predicted to have porosity of articular surfaces of elbow joint $(R=0.30)$. But the caution is required when interpreting this result. Firstly, significant correlation was observed in the females' right bones only. Secondly, the etiology of porosity is not clear. Septal aperture did not correlate with osteophytosis, and eburnation (correlation is low and negative). This result contradicts the mechanical theory of SA formation (SA is a result of the impingement of overgrown ulnar process on the humeral septum). One explanation can be that osteophytes limit the natural motion of the joint to constitute a repair response an attempt at stabilizing the degenerating joint. It can prevent from septal aperture formation, or/and its enlargement. As in the case of osteophytes, eburnation limits elbow mobility, and thereby can exclude septal aperture formation. Further analyses of the relationship between septal aperture and osteoarthritic changes formation are needed. It is important for anthropological, and medical researches.
\end{abstract}

\section{Keywords}

Septal Aperture, Osteoarthritis, Osteophytosis, Porosity, Eburnation, Skeletal Population

\section{Introduction}

The septal aperture of humerus (SA) (called also subtrochlear foramen, intercondylar foramen) is a perforation 
in the bony lamina that separates the olecranon and coronoid fossae (Mays, 2008). The lamina is present until seven years of age and after it is occasionally absorbed to subtrochlear foramen (Kate et al., 1970). In man, the frequency of the foramen has ranged from about $0.3 \%$ to $60 \%$ in different races (for the details see Krishnamurthy et al., 2011; Patel et al., 2013; Raghavendra et al., 2014).

The cause of septal aperture is still under the question. Many theories have been suggested in order to explain the etiology of the trait but the problem has not been solved yet. The marked variation in a frequency of septal aperture between different human populations is given as an evidence for genetic etiology of the trait (Granville, 1967; Mays, 2008). Number of researchers suggested that septal aperture is just connected with the impingement on humeral septum by coronoid and olecranon process (a wider range of flexion and extension at the elbow join, overgrown olecranon or coronoid process) (Granville, 1967; Benfer \& Tappen, 1968; Mays, 2008). The septal aperture is attributed to atrophy of bone after ossification (Houshian et al., 2001). Granville (1967), Benfer and Tappen (1968) obtained the converse correlation between septum thickness and ulna processes and suggested that more protruding ulna processes impinge bony lamina which causes septal perforation. Other researchers give ligamentous and/or muscles laxity as a possible cause of septal aperture formation (Mays, 2008; Papaloucas et al., 2011; Myszka, in press). They hypothesized that weaker muscles can lead to higher joint laxity, which causes joint hypermobility, impingement of ulnar processes on the humeral lamina, and can finally lead to lamina perforation (Mays, 2008; Papaloucas et al., 2011; Myszka, in press). There are some other assumptions according to the etiology of subtrochlear foramen. It has been trying to analyze the relationship between septal aperture and osteoarthritis, osteoporosis (Papaloucas et al., 2011), or bone robusticity (Trotter, 1934; Benfer \& McKern, 1966; Benfer \& Tappen, 1968; Silveira et al., 2007; Myszka, in press), but the results are questioned (Mays, 2008).

Because of ambiguity of the causes of septal aperture formation it seems to be necessary to continue the analyses of the problem. Therefore the relationship between septal aperture and osteoarthritis is examined here. Osteoarthritis (OA) is a biomechanical and biochemical progressive disorder of the joint system, which leads to deterioration of the articular cartilage, osteophyte formation, eburnation, joint space reduction, and incongruity at the joint surface and margins (Goldring, 2007, Terrono \& Horner, 2000). Some anthropologists claim that extensive physical activity, and mechanical loading can lead to articular degeneration (Molnar et al., 2011, Weiss \& Jurmain, 2007); therefore in many cases the analysis of osteoarthritis in skeletal populations is carried out in accordance to the past groups physical activity reconstruction (Larsen, 1997; Cope et al., 2005; Liverse et al., 2007; Molnar et al., 2011). Taking the above one would expect that individuals with more loaded elbow joint might have greater tendency to septal aperture formation, and more pronounced osteoarthritis.

Given the controversy and uncertainty according to the etiology of septal aperture, the further studies seem to be necessary. Knowledge about the phenomenon of subtrochanter aperture is important for both anthropological, and medical studies. The aim of the present study is to investigate the relationship between septal aperture, and osteoarthritic changes.

\section{Materials and Methods}

The sample comes from a medieval (10th to 14th century) skeletal population from Cedynia, Poland. Skeletons of 102 males (66 young adult, 54 middle adult) and 99 females (61 young adult, 38 middle adult) were examined. Recommended methods were applied to estimate the age and sex of the individuals (Ferembach et al., 1979; Buikstra \& Ubelaker, 1994). Features of cranium and pelvis were assessed for sex estimation. Age was estimated through the analysis of the degree of the changes on the surface of pubic symphysis, and cranial suture obliteration. The age classes were based on Buikstra and Ubelaker (1994): Young Adult (20 - 34 years), Middle Adult (35 - 49 years). According to the high frequency of degenerative changes of bones, individuals older than 50 years were not included.

Individuals were analyzed according to septal aperture, and its relationship to elbow osteoarthritis. Septal aperture was scored as absent (0) or present (1). The frequency of septal aperture was calculated according to sex, and skeletal side.

Osteoarthritis was examined according to standard methods by Buikstra and Ubelaker (1994). Three types of osteoarthritic changes were examined: osteophytic lipping, porosity, and eburnation (Buikstra \& Ubelaker, 1994). OA was scored if any one or a combination of osteophytic lipping, porosity, or eburnation were observed in articular surface of distal humerus, proximal ulna. Data were recorded as present, or absent (Klaus et al., 
2009). The analysis were made on both left and right limb bones. To eliminate from the analysis individuals with rheumatoid arthritis, bones of hands, feet, and other joints were also examined. Only individuals without any traumas (bones fractures), bones deformities were included.

Septal aperture and osteoarthritic changes were tested for significant skeletal side, sex differences using the test for two components of the structure. Spearman rank order correlation coefficients were used to evaluate the relationship between septal aperture and osteoarthritis. Critical alpha-levels were set at 0.05 . Statistical analyses were run using the Statistica 10.0 PL software.

\section{Results}

The frequency of septal aperture in the population from Cedynia is $7.5 \%$. In this skeletal group the difference between septal aperture prevalence in males and females is not statistically significant (left skeletal side: $p=$ 0.82 ; right skeletal side: $p=0.41$ ). There are no differences between the frequency of septal aperture on the left and right skeletal side (Table 1). The frequency data for septal aperture in accordance to sex, and skeletal side are given in Table 1.

The frequency data for osteoarthritic changes in accordance to sex, and skeletal side are given in Table 2. There are no differences between the frequency of osteoarthritic changes on the left and right skeletal side (Table 2). In analyzed population males and females do not differ according to the frequency of osteoarthritic changes. Only in the case of porosity (right bones) differences were statistically significant $(p=0.037)$.

In Cedynia only females with observed porosity of elbow joint articular surfaces tend to have septal aperture $(\mathrm{R}=0.30)$ (Table 3).

Table 1. Frequencies of septal aperture with respect to sex and skeletal side, and skeletal side differences in septal aperture prevalence.

\begin{tabular}{cccccccccc}
\hline \multirow{2}{*}{ Skeletal side } & \multicolumn{3}{c}{ Males } & \multicolumn{3}{c}{ Females } \\
\cline { 2 - 10 } & $\mathrm{N}$ & $\mathrm{n}$ & \% & $p$ & $\mathrm{~N}$ & $\mathrm{n}$ & \%n & $p$ \\
\hline Left & 66 & 5 & 7.6 & 0.71 & 53 & 4 & 7.6 & 0.64 \\
Right & 64 & 6 & 9.4 & & 56 & 3 & 5.4 &
\end{tabular}

"Statistically significant at $p \leq 0.05$; N: number of humeri; n: number of humeri with septal aperture; \%n: frequency of humeri with septal aperture.

Table 2. Frequencies of osteoarthritic changes with respect to sex and skeletal side, and skeletal side differences in osteoarthritic changes prevalence.

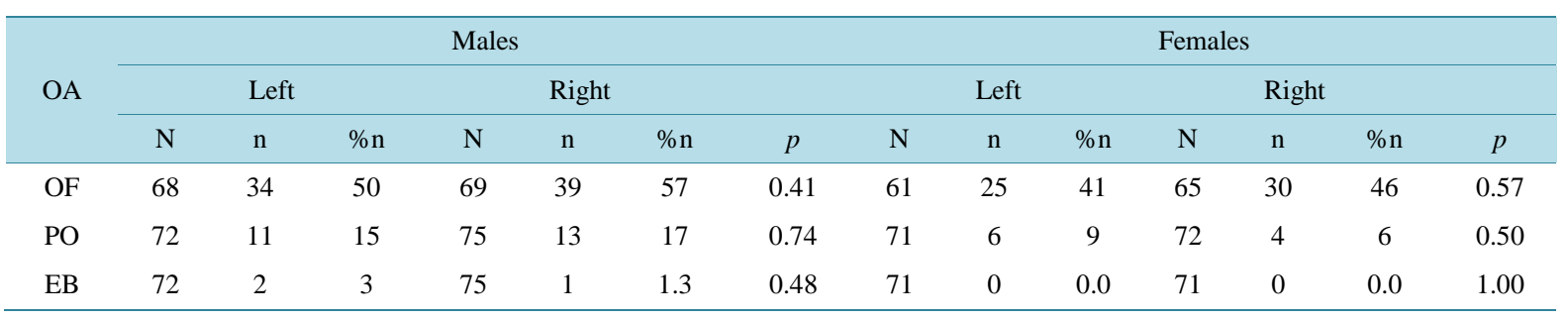

*Statistically significant at $p \leq 0.05$; N: number of elbow joints; n: number of elbows with osteoarthritic changes; \%n: frequency of elbows with osteoarthritic changes; OA: osteoarthritic change; OF: osteophytosis; PO: porosity; EB: eburnation.

Table 3. Spearman rank order correlation coefficient (R) among septal aperture and osteoarthritic changes in elbow joint. Bold correlations: $p \leq 0.05$.

\begin{tabular}{|c|c|c|c|c|}
\hline \multirow{3}{*}{$\mathrm{OA}$} & \multicolumn{4}{|c|}{$\mathrm{R}$} \\
\hline & \multicolumn{2}{|c|}{ Males } & \multicolumn{2}{|c|}{ Females } \\
\hline & Left & Right & Left & Right \\
\hline OF & -0.16 & -0.18 & -0.12 & -0.09 \\
\hline $\mathrm{PO}$ & -0.08 & 0.01 & -0.06 & $0.30^{*}$ \\
\hline EB & -0.04 & -0.05 & - & - \\
\hline
\end{tabular}

*Statistically significant at $p \leq 0.05$; OA: osteoarthritic change; OF: osteophytosis; PO: porosity; EB: eburnation. 


\section{Discussion}

In the population from Cedynia the relationship between septal aperture and osteoarthritic changes is ambiguous. In this study, small, although significant correlation between septal aperture, and porosity of articular surfaces of elbow was found $(\mathrm{R}=0.30)$. This relationship was observed for females, and for the right skeletal side only. But these results do not entitle to draw any firm conclusions about relationship between these two features. Firstly, because significant correlation was observed in the females' left bones only (Table 3). Secondly, as it was pointed out by Rothschild (1997), Weiss and Jurmain (2007), the cause of porosity is not clear; it is a bone change that appears in non weight-bearing joint region, and therefore it can reflect some secondary effect due to e.g. bone/cartilage nutrition. Taking the above, it would be unwise to expect, without any doubts, that septal aperture is connected in a simple way with porosity of articular surfaces of elbow. Coexistence of these two features does not necessarily mean the same origins. But the obtain results suggest to continue the analysis of that problem.

There was no relationship between SA, and osteophytosis of the articular surfaces of distal humerus and proximal ulna. It might mean that osteophytes on ulnar processes do not impact the SA formation. Taking the mechanical theory of septal aperture formation, claiming that SA is connected with the impingement on the humeral septum by the ulna process, as a result of e.g. an overgrown coronoid or olecranon process (see Mays, 2008; Krishnamurthy et al., 2011), one can expect that osteophytosis, especially on ulnar processes, increases the risk of septal aperture. The obtained results seem to contradict this theory. One explanation can be that osteophytes limit the natural motion of the joint (Pottenger et al., 1990), and they are thought to be a repair response of bone in order to stabilize the degenerating joint (Menkes \& Lane, 2004; Fukui \& Sandell, 2007). Taking this it can be hypothesise that osteophytosis prevent from septal aperture formation, or/and its enlargement. But that theory needs some further studies.

Osteophytosis is usually connected with aging process (Bridges, 1992; Roger \& Waldron, 1995; see also Weiss \& Jurmain, 2007), while septal aperture is not considered to be correlated with age (Mays, 2008; Koyun et al., 2011; Myszka, in press). It might suggest the different etiology of these two features.

In this study there was no relationship between septal aperture and eburnation. Eburnation is the result of a polishing process produced by bone rubbing on bone (Rothschild, 1997). Because it is a nonspecific finding in any severe arthritis (Resnick \& Niwayama, 1988), and because of the fact that the prevalence of this trait is very low in the present study, it is not discussed here. But taking into account, that eburnation occurs when cartilage is lost, and when bone rubs to bone (Rothschild, 1997), it would be difficult not to assume that mobility in elbow joint is not limited. And, similarly to osteophytosis, taking into account mechanical theory of SA etiology, eburnation seems to exclude septal aperture formation.

The analyses of the relationship between septal aperture, and osteoarthritis are rare, and the researchers are cautious. Papaloucas et al. (2011) are skeptical, claiming that although osteoarthritis is given as one of possible cause of septal aperture appearance, but they did not found such a relationship in their study. Mays (2008) questioned the existence of the relationship between septal aperture and osteoarthritis argued that septal aperture form in early adult life, before the osteoarthritic changes characteristically manifest. Besides, it must be emphesise that many anthropologists underline the multifactorial etiology of osteoartritis, indicating physical activity, genes (Manek et al., 2003; Valdes \& Spector, 2009), age, bone density (Lajeunesse \& Reboul, 2007; Teichtahl et al., 2005), hormones (Spector \& Campion, 1989), vitamin D deficiency (Lane et al., 1999; Mc Alindon et al., 1996), or obesity (Manek et al., 2003) as a possible factors in osteoarthritic changes formation. Therefore, a simple explanation of the existence or absence of the correlation between septal aperture, and osteoarthritis cannot be drawn.

Further analyses of the relationship between septal aperture and osteoarthritic changes formation seem to be necessary. It is important from medical (diagnosis, preventing, an assessment of the risk of changes), and anthropological point of view (reliable reconstruction of past people biology, and behavior).

\section{References}

Benfer, R. A., \& McKern, T. W. (1966). The Correlation of Bone Robusticity with the Perforation of the Coronoid-Olecranon Septum in the Humerus of Man. American Journal of Physical Anthropology, 24, 247-256. http://dx.doi.org/10.1002/ajpa.1330240213

Benfer, R. A., \& Tappen, N. C. (1968). The Occurrence of Septal Perforation of the Humerus in the Non-Human Primate Species. American Journal of Physical Anthropology, 29, 19-28. http://dx.doi.org/10.1002/ajpa.1330290111 
Bridges, P. S. (1992). Prehistoric Arthritis in the Americas. Annual Review in Anthropology, 21, 67-91. http://dx.doi.org/10.1146/annurev.an.21.100192.000435

Buikstra, J. E., \& Ubelaker, D. H. (1994). Standards for Data Collection from Human Skeletal Remains. Arkansas Archeological Survey Research, no. 44.

Cope, J. M., Barryman, A. C., Martin, D. L., \& Potts, D. D. (2005). Robusticity and Osteoarthritis at the Trapeziometacarpal Joint in a Bronze Age Population from Tell Abraq, United Arab Emirates. American Journal of Physical Anthropology, 126, 391-400. http://dx.doi.org/10.1002/ajpa.20097

Ferembach, D., Schwidetzky, I., \& Stloukal, M. (1979). Empfehlungen für die alters- und Geschlechtsdiagnose am Skelett. Homo, 30, 1-32.

Fukui, N., \& Sandell, L. J. (2007). Anabolic Mediators of Cartilage Healing. In F. Bronner, \& M. C. Farach-Carson, (Eds.), Bone and Osteoarthritis (Vol. 4, pp. 97-108). London: Springer-Verlag. http://dx.doi.org/10.1007/978-1-84628-701-5_6

Goldring, M. B. (2007). Cytokines, Growth Factors, and Bone-Derived Factors in Cartilage. In F. Bronner, \& M. Farach-Carson (Eds.), Bone and Osteoarthritis (Vol. 4, pp. 41-63). London: Springer-Verlag.

Granville, E. V. (1967). Perforation of the Coronoid-Olecranon Septum Humero-Ulnar Relationship in Netherlands and African Populations. American Journal of Physical Anthropology, 26, 85-92. http://dx.doi.org/10.1002/ajpa.1330260111

Houshian, S., Mehdi, B., \& Larsen, M. S. (2001). The Epidemiology of Elbow Fracture in Children: Analysis of 355 Fractures, with Special Reference to Supracondylar Humerus Fractures. Journal of Orthopaedic Science, 6, 121-125. http://dx.doi.org/10.1007/s007760100024

Kate, B. R., \& Budey, P. N. (1970). A Note on a Septal Apertures in the Humerus of Central Indians. Eastern Anthropologist, 33, 105-110

Klaus, H. D., Larsen, C. S., \& Tam, M. E. (2009). Economic Intensification and Degenerative Joint Disease: Life and Labor on the Postcontact North Coast of Peru. American Journal of Physical Anthropology, 139, 204-221. http://dx.doi.org/10.1002/ajpa.20973

Koyun, N., Aydinlioğlu, A., \& Gümrukcüoğlu, F. N. (2011). Aperture in Coronoi-Olecranon Septum: A Radiological Evaluation. Indian Journal of Orthopaedics, 45, 392-395. http://dx.doi.org/10.4103/0019-5413.83945

Krishnamurthy, A., Yelicharla, A. R., Takkalapalli, A., Manishamappa, V., Bovinndala, B., \& Chandramohan, M. (2011). Supratrochlear Foramen of Humerus-A Morphometric Study. International Journal of Biological \& Medical Research, 2 , 829-831.

Larsen, C. S. (1997). Bioarchaeology: Interpreting Behavior from the Human Skeleton. New York: Cambridge University Press. http://dx.doi.org/10.1017/CBO9780511802676

Lajeunesse, D., \& Reboul, P. (2007). The Role of Bone in the Development of Osteoarthritis. In F. Bronner, \& M. Farach-Carson (Eds.), Bone and Osteoarthritis (Vol. 4, pp. 19-39). London: Springer-Verlag.

Lane, N. E., Gore, L. R., Cummings, S. R., Hochberg, M. C., Scott, J. C., Williams, E. N., \& Nevitt, M. C. (1999). Serum Vitamin D Levels and Incident Changes of Radiographic Hip Osteoarthritis: A Longitudinal Study. Arthritis \& Rheumatism, 42, 854-860. http://dx.doi.org/10.1002/1529-0131(199905)42:5<854::AID-ANR3>3.0.CO;2-I

Liverse, A. R., Weber, A. W., Bazaliiskiy, V. I., Goriunova, O. I., \& Savel'ev, N. A. (2007). Osteoarthritis in Siberia's Cis-Baikal: Skeletal Indicators of Hunter-Gatherer Adaptation and Cultural Change. American Journal of Physical Anthropology, 132, 1-16. http://dx.doi.org/10.1002/ajpa.20479

Manek, N. J., Hart, D., Spector, T. D., \& MacGregor, A. J. (2003). The Association of Body Mass Index and Osteoarthritis of the Knee Joint: An Examination the Genetic and Environmental Influences. Arthritis \& Rheumatism, 48, 1024-1029. http://dx.doi.org/10.1002/art.10884

Mays, S. (2008). Septal Aperture of the Humerus in a Mediaeval Human Skeletal Population. American Journal of Physical Anthropology, 136, 432-440. http://dx.doi.org/10.1002/ajpa.20826

Mc Alindon, T. E., Felson, D. T., Zhang, Y., Hannan, M. T., Aliabadi, P., Weissman, B., Rush, D., Wilson, P. W. F., \& Jacques, P. (1996). Relation of Dietary Intake and Serum Levels of Vitamin D to Progression of Osteoarthritis of the Knee among Participants in the Framingham Study. Annals of Internal Medicine, 125, 353-359. http://dx.doi.org/10.7326/0003-4819-125-5-199609010-00001

Menkes, C. J., \& Lane, N. E. (2004). Are Osteophytes Good or Bad? Osteoarthritis and Cartilage, 12, 53-54. http://dx.doi.org/10.1016/j.joca.2003.09.003

Molnar, P., Ahlstrom, T. P., \& Leden, I. (2011). Osteoarthritis and Activity-An Analysis of the Relationship between Eburnation, Musculoskeletal Stress Markers (MSM) and Age in Two Neolithic Hunter-Gatherer Populations from Gotland, Sweden. International Journal of Osteoarchaeology, 21, 283-291. http://dx.doi.org/10.1002/oa.1131

Myszka, A. (In Press). Septal Aperture Etiology: Still More Questions than Answers. Folia Morphologica. 
Papaloucas, C., Papaloucas, M., \& Stergiulas, A. (2011). Rare Cases of Humerus Septal Apertures in Greeks. Trends in Medical Research, 6, 178-183. http://dx.doi.org/10.3923/tmr.2011.178.183

Patel, S. V., Sutaria, L. K., Nayak, T. V., Kanjiya, D. P., Patel, B. M., \& Aterkar, S. H. (2013). Morphometric Study of Supratrochlear Foramen of Humerus. International Journal of Biomedical and Advance Research, 4, 89-92.

Pottenger, L. A., Philips, F. M., \& Draganich, L. F. (1990). The Effect of Marginal Osteophytes on Reduction of VarusValgus Instability in Osteoarthritic Knees. Arthritis \& Rheumatism, 33, 853-858. http://dx.doi.org/10.1002/art.1780330612

Raghavendra, K., Reddy, A. K., Shirol, V. S., Dixit, D., \& Desai, S. P. (2014). Morphometric Analysis of Septal Aperture of Humerus. International Journal of Medical Research \& Health Sciences, 3, 269-272. http://dx.doi.org/10.5958/j.2319-5886.3.2.058

Resnick, D., \& Niwayama, G. (1988). Diagnosis of Bone and Joint Disorders. Philadelphia, PA: Saunders.

Roger, J., \& Waldron, T. (1995). A Field Guide to Joint Disease in Archaeology. New York: Willey.

Rothschild, B. M. (1997). Porosity: A Curiosity without Diagnostic Significance. American Journal of Physical Anthropology, 104, 529-533. http://dx.doi.org/10.1002/(SICI)1096-8644(199712)104:4<529::AID-AJPA7>3.0.CO;2-M

Silveira, F. B. C., Junior, V. M., \& Fazan, V. P. S. (2007). Anthropometric Evaluation of the Humerus in the Presence and Absence of the Septal Foramen. International Journal of Morphology, 25, 158 (Abstract).

Spector, T. D., \& Campion, G. D. (1989). Generalized Osteoarthritis: A Hormonal Mediated Disease. Annals of the Rheumatic Diseases, 48, 523-527. http://dx.doi.org/10.1136/ard.48.6.523

Teichtahl, A. J., Wluka, A. E., Proietto, J., \& Cicuttini, F. M. (2005). Obesity and Female Sex, Risk Factors for Knee Osteoarthritis that May Be Attributable to Systemic or Local Leptin Biosynthesis and Cellular Effects. Medical Hypotheses, 65, 312-315. http://dx.doi.org/10.1016/j.mehy.2005.02.026

Terrono, A. L., \& Horner, G. (2000). Carpometacarpal Pain: Is It Osteoarthritis? Musculoskeletal Medicine, 17, 744-753.

Trotter, M. (1934). Septal Apertures in Humerus of American Whites and Negroes American. American Journal of Physical Anthropology, 19, 213-227. http://dx.doi.org/10.1002/ajpa.1330190221

Valdes, A. M., \& Spector, T. D. (2009). The Contribution of Genes to Osteoarthritis. Medical Clinics of North America, 93, 45-66. http://dx.doi.org/10.1016/j.mcna.2008.08.007

Weiss, E., \& Jurmain, R. (2007). Osteoarthritis Revised: A Contemporary Review of Etiology. International Journal of Osteoarchaeology, 17, 437-450. http://dx.doi.org/10.1002/oa.889 